\title{
Outcome in colorectal adenocarcinoma: two seven-year studies of a population
}

\author{
Nanette L M Gordon, Audrey A Dawson, Bruce Bennett, George Innes, Oleg Eremin, Peter F Jones
}

Abstract

Objective-To record every patient with proved colorectal adenocarcinoma presenting from a defined population over two years in $1968-9$ and during 1980-2, and to compare treatment and outcome over seven years.

Design-Retrospective in $1968-9$ and prospective in 1980-2.

Setting-Aberdeen general hospitals.

Subjects-Every patient presenting to the four general surgical units with histological proof of colorectal adenocarcinoma.

Main findings - On average, one new patient proportion of patients aged 65 and over rose from $67 \%$ to $71 \%$. An operation was performed on 385 patients in 1968-9 and on 399 during 1980-2. At laparotomy the proportion of patients who seemed to be curable and had a radical operation rose slightly, from $56 \%$ to $61 \%$, and operative mortality fell from $9 \%$ to $5 \%$. In all there were 421 survivors of curative surgery, and seven years later three quarters were either alive $(51 \%)$ or had died without recurrence $(25 \%)$. In both studies some $40 \%$ of patients were considered incurable when they presented, but the number who had a palliative

Conclusions-The contribution of radical surgery to the treatment of colorectal adenocarcinoma is substantial, with three quarters of patients so treated showing no evidence of recurrence after seven years. Operative mortality in an elderly population is now low, and improvement in late outcome is more likely to come from developments in adjuvant therapy than in operative technique. A continuing problem is that $40 \%$ of patients are not curable when they present, although palliative resection can now be offered to over $80 \%$. University of Aberdeen, Aberdeen AB9 2ZD

Nanette L M Gordon, research fellow

Audrey A Dawson, consultant haematologist

Bruce Bennett, reader

Department of Public Health, University of Aberdeen

George Innes, reader

Department of Surgery, University of Aberdeen

Oleg Eremin, regius professor

Peter F Jones, emeritus

clinical professor

Correspondence to:

Professor P F Jones.

Polwarth Building,

Foresterhill, Aberdeen

AB9 2ZD

BMF 1993;307:707-10 natural to an elderly population will account for considerable late mortality. Secondly, results are seriously hope of cure when they present, and virtually all die within three years. Finally, although radical surgery is often successful in patients who seem to be curable at the time of operation, follow up reveals that occult local or distant spread was already present in one quarter. presented each week per 100000 population. The resection rose from $59 \%$ to $85 \%$.

It is interesting to review these facts in the light of two studies, separated by 12 years, of 800 patients residing in the Grampian region of Scotland, an area known to have a high incidence of colorectal cancer. ${ }^{2}$ The two studies, both over 24 months, took place in 1968-9 and during 1980-2, and both recorded outcome over seven years. The details of the first study have been published ${ }^{2}$; here the second study is reported and the two are compared.

\section{Methods}

Virtually all major illness in a population of some 400000 is treated in the hospitals in Aberdeen. Throughout both 1968-9 and 1980-2 patients from this area with colorectal cancer were admitted or transferred into one of the four general surgical units in the city, and the aim of both studies was to examine the record of everyone so treated. Methods of diagnosis and treatment changed little between the two periods, with minimal use of adjuvant therapy. In both studies the major source of information was the file of histopathological reports in the university department of pathology, to which all tissue biopsied or resected in the Grampian region is sent.

In 1968-9 the aim was to recover every case occurring in the Grampian region, so 10 patients found after a search of records of postmortem examinations and a small number with only a positive report on a barium enema were included. During 1978-9 details of all these patients were recovered from hospital notes and from their family doctors. The 1980-2 study was confined to every patient for whom a histopathological report of colorectal adenocarcinoma was issued. Whenever the individual was in the care of a unit in Aberdeen the patient was visited by one of us (NG) and registered, and details of care were immediately checked with medical staff. The progress of all survivors was followed at yearly intervals until 1987. During 1992 the later progress of all patients surviving in 1987 was determined, and outcome is known for all but three of the 406 patients who were registered.

Comparisons in this report are limited to those patients who came to operation and had a positive report of adenocarcinoma-385 in the first study, 399 in the second. In both studies a patient was defined as having a "radical operation" when a standard resection of colon or rectum, with the associated area of lymphatic drainage, was performed and the surgeon considered that all neoplastic tissue had been removed. The liver was assessed by inspection and palpation. Dukes's staging ${ }^{3}$ was available for the second but not for the first study. affected by the fact that $40 \%$ of patients are beyond

Table I shows the distribution of all patients from both studies according to age, sex, site of tumour, and treatment provided. In the 1980-2 study a total of 91 patients $(22 \%)$ presented for emergency treatment. 
TABLE I-Results in two series of patients with colorectal adenocarcinoma

\begin{tabular}{|c|c|c|c|c|}
\hline & \multicolumn{2}{|l|}{ 1968-9 Series } & \multicolumn{2}{|c|}{ 1980-2 Series } \\
\hline $\begin{array}{l}\text { No of patients } \\
\text { No }(\%) \text { of women }\end{array}$ & & $433^{\star}$ & & 406 \\
\hline \multicolumn{5}{|l|}{ Age (years): } \\
\hline$<55$ & & $49(11)$ & & $37(9)$ \\
\hline $55-64$ & & $95(22)$ & & $81(20)$ \\
\hline $65-74$ & & $160(37)$ & & $142(35)$ \\
\hline$\geqslant 75$ & & $122(30)$ & & $146(36)$ \\
\hline No operation & & $48^{\star}$ & & 7 \\
\hline No $(\%)$ of operations & & $385(89)$ & & $399(98)$ \\
\hline Radical & $215(56)$ & & \multirow{2}{*}{\multicolumn{2}{|c|}{$242(61)$}} \\
\hline Palliative & $170(44)$ & & & \\
\hline Resection & $101(59)$ & & $133(85)$ & \\
\hline Laparotomy & $69(41)$ & & $24(15)$ & \\
\hline No $(\%)$ of postoperative deaths: & & $66(17)$ & & $38(10)$ \\
\hline Radical operations & \multirow{2}{*}{\multicolumn{2}{|c|}{$\begin{array}{c}20(9) \\
46(27) \dagger\end{array}$}} & $13(5)$ & \\
\hline Palliative operations & & & $25(16) t$ & \\
\hline Site of carcinoma & \multirow{2}{*}{\multicolumn{3}{|c|}{$150(34)$}} & \\
\hline Right colon & & & & $137(34)$ \\
\hline Left colon & \multicolumn{3}{|c|}{$114(26)$} & $123(30)$ \\
\hline Rectum & \multicolumn{3}{|c|}{$169(39)$} & $146(35)$ \\
\hline
\end{tabular}

*Including 10 patients diagnosed at necropsy and some patients with positive results on barium enema only. tz Test for proportions showed a significant difference in proportion of deaths after palliative operations $(\mathrm{p}=0.0096)$ but not after radical operations $(p-0 \cdot 1074)$

$\ddagger$ Right colon includes transverse colon; left colon includes splenic flexure and sigmoid colon; rectum includes retrosigmoid junction. give a true picture of the effects of treatment, so table III compares the life expectancy of the patients treated radically with that of the general population. The figures for 1980-2 are noticeably poorer, especially for rectal carcinoma, and reflect the higher proportion of deaths which were due to intercurrent disease.

Seven general surgeons shared the care of $95 \%$ of the 242 patients in the second study: two surgeons performed $40 \%$ of the operations, with the other five each treating $10-13 \%$ of the remaining patients. Mortality and recurrence rates showed no major differences among the seven surgeons.

\section{Discussion}

Two aspects of the care of patients with colorectal cancer are currently receiving particular consideration: can adjuvant therapy reduce recurrence among patients who seem at operation to be potentially curable, and do surgeons specialising in this field deliver noticeably better results than other general surgeons? The two studies reported here may contribute to this debate because both are believed to provide a complete and unselected picture of the presentation of colorectal cancer in a defined and fairly static population.

Increasing longevity in the general population was reflected in $1980-2$ when more than half $(56 \%)$ of the patients were 70 or more years old. No change occurred in the proportion of carcinomas in the right colon, unlike in reports from North Americas and Northern Ireland. ${ }^{6}$ The scope for radical resection changed little, from $56 \%$ to $60 \%$, but the overall resection rate rose from $82 \%$ to $94 \%$ due to greater use of palliative resection. This rise is probably due to developments in surgical practice and in preoperative and postoperative care, which also contributed to the appreciable falls in operative mortality. During 1980-2 the chance of operation was offered widely to an unselected and noticeably elderly population with an overall mortality of $10 \%$ and a mortality of $5 \%$ for radical resection. Comparisons can be difficult to make, but some recent studies report a rate of $5-7 \%$ for radical resection, ${ }^{78}$ and with an aging population these figures are unlikely to fall much further.

There remains the daunting fact that at laparotomy some $40 \%$ of patients in both series were already surgically incurable, despite good communication between family doctors and the hospitals in the area and admission of these patients without delay. Most patients in this group had palpable metastases in the liver. Serial scanning suggests that by the time hepatic metastases are evident at laparotomy they have been present for several years, ${ }^{9}$ so symptoms can have troubled these patients only long after metastases had developed. This raises the question whether population screening for faecal occult blood should be adopted. More cancers can be detected at Dukes's stage A, but it remains to be established whether this important result for the few outweighs

TABLE II-Outcome seven years after radical operation. Values are numbers (percentages) of patients

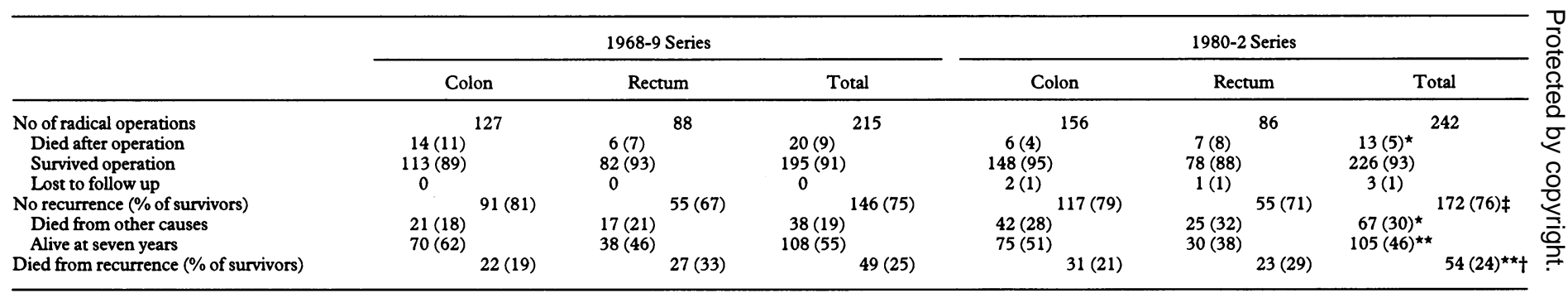

${ }^{\star}$ Mean age 76.5 years.

$\star \star$ Mean age 67.5 years.

t38 Patients (70\%) were Dukes's stage $C$ in the 172 patients without recurrence

$\$ 73$ Patients $(42 \%)$ were Duke's stage $C$ in the 54 patients with recurrence. 


\begin{tabular}{|c|c|c|c|c|c|c|c|c|}
\hline & \multicolumn{4}{|c|}{ 1968-9 Series } & \multicolumn{4}{|c|}{ 1980-2 Series } \\
\hline & \multicolumn{2}{|c|}{ Colon } & \multicolumn{2}{|c|}{ Rectum } & \multicolumn{2}{|c|}{ Colon } & \multicolumn{2}{|c|}{ Rectum } \\
\hline & $\underset{(n=46)}{\text { Men }}$ & $\begin{array}{l}\text { Women } \\
(n=70)\end{array}$ & $\underset{(n=45)}{\operatorname{Men}}$ & $\begin{array}{l}\text { Women } \\
(n=40)\end{array}$ & $\underset{(n=67)}{\text { Men }}$ & $\begin{array}{l}\text { Women } \\
(n=78)\end{array}$ & $\begin{array}{c}\text { Men } \\
(n=50)\end{array}$ & $\begin{array}{l}\text { Women } \\
(n=32)\end{array}$ \\
\hline $\begin{array}{l}\text { Alive at seven years: } \\
\text { No (\%) observed } \\
\text { No expected } \\
\text { Corrected percentage expected }\end{array}$ & $\begin{array}{l}25(54) \\
33 \cdot 4 \\
75\end{array}$ & $\begin{array}{l}43(61) \\
55 \cdot 6 \\
77\end{array}$ & $\begin{array}{l}13(29) \\
31 \cdot 2 \\
42\end{array}$ & $\begin{array}{l}24(60) \\
34 \cdot 4 \\
70\end{array}$ & $\begin{array}{l}27(40) \\
43 \cdot 8 \\
64\end{array}$ & $\begin{array}{l}37(47) \\
59 \cdot 7 \\
62\end{array}$ & $\begin{array}{l}15(30) \\
33 \cdot 1 \\
45\end{array}$ & $\begin{array}{l}11(34) \\
26 \cdot 1 \\
42\end{array}$ \\
\hline
\end{tabular}

`Figures for 1968-9 from Clarke et aP; figures for 1980-2 are life expectation of general Scottish population adjusted for age and sex, derived from life tables in registrar general's report for $1982 .^{*}$

the additional anxieties, work, and expense which are involved. ${ }^{10}$

The need to extend follow up over more than the traditional five years was again shown: in the 1980-2 group $10(18 \%)$ of the 54 patients who died with metastases survived for between five and a half and seven years.

The substantial contribution that radical resection can make to outcome was confirmed in both studies, with $75 \%$ of the patients who had radical surgery showing no evidence of recurrence over seven years, or up to the time of death from an unrelated cause (table II). Among the 1980-2 group, for instance, 111 (49\%) of 226 patients were placed in the prognostically dubious Dukes's stage C yet 43 survived for seven years, and in another 30 there was no evidence of recurrence at the time of death.

In both studies, however, $23-25 \%$ of patients who had a potentially curative resection died eventually from "recurrence," mostly in the liver. This is an interesting figure because when Finlay and McArdle carried out computed tomography and ultrasonic scanning of 70 patients immediately after a radical colorectal resection they found that 24 had scans positive for, or suspicious of, occult metastases. Eight results later proved to be false positives, but the other 16 patients $(23 \%)$ went on to develop overt metastases. ${ }^{11}$ It seems, therefore, that in our 457 potentially curable patients, and these 70 similar patients, about one quarter came to operation only after occult metastasis, generally to the liver, had taken place. This strongly suggests that in this group surgeons are up against a fact of pathology which is not susceptible to any extension of resectional surgery. Our extended experience confirms growing evidence that surgical results, though good, are unlikely to improve significantly, and leads directly to the current exploration of the potential of adjuvant therapy.

\begin{tabular}{|l|}
\hline Clinical implications \\
\hline More than half (56\%) of patients who present \\
with colorectal adenocarcinoma are over 70 \\
years of age \\
- Some $60 \%$ of new patients are potentially \\
curable with radical surgery; this study found \\
that seven years after operation three quarters of \\
these patients were alive (75\%) or had died \\
without recurrence of adenocarcinoma (25\%) \\
The mortality of radical surgery is now low \\
(5-6\%) and developments in adjuvant therapy \\
rather than in surgical technique are most likely \\
to benefit the $25 \%$ of apparently curable patients \\
who have occult metastases at time of operation \\
- Symptoms develop too late to warn the other \\
$40 \%$ of patients, who are beyond cure when they \\
present, and methods of screening are required \\
to identify this group at a curable stage
\end{tabular}

The originators of the adjuvant $x$-ray and 5fluorouracil infusion study (AXIS) trial of the United Kingdom Coordinating Committee for Cancer Research's colorectal cancer subcommittee reviewed the published trials of chemotherapy and radiotherapy. ${ }^{12}$ In chemotherapy, after the trial of Taylor et $a l^{3}$ the most hopeful method seemed to be to infuse fluorouracil and heparin into the portal vein for seven days after resection. However, evidence for the effect of this treatment on survival is not consistent, ${ }^{13} 14$ and this may be because once micrometastases in the liver exceed $0.5 \mathrm{~mm}$ diameter they acquire a circulation from the hepatic artery. ${ }^{15}$ The role of intraportal infusion may lie in the destruction of only the earliest tumour embolisms in the liver. The alternative is to administer fluorouracil systemically for some months in combination with another agent. Such a course may be of value ${ }^{16}$ - perhaps because it can mediate its effects through the arterial tree-but further large scale trials are needed to define the best regimen.

A few of our patients had prolonged symptoms from local recurrence of a rectal carcinoma, so the results of the AXIS trial of radiotherapy will be important, as will critical assessment of the contribution of mesorectal excision. ${ }^{17}$

Radical resection will, for some time, play the major role in the treatment of colorectal cancer, so the debates over the role of the surgeon with a special interest in the subject is relevant. The workload is substantial-about one new patient per week per 100000 population. Until general surgical services are staffed to meet the whole of the demand, ${ }^{18}$ our own and other studies show that a share of the work can be well provided by general surgeons who have had a thorough training in abdominal surgery. ${ }^{19}$ Now that cross reference among colleagues - each with a special interestis becoming customary, ${ }^{20}$ this will allow the skills of the surgeon with a special interest in coloproctology to be concentrated in specific areas. Patients with carcinoma in the subperitoneal rectum benefit from expertise in radical dissection in the pelvis and in conservation of the anal sphincter. The experienced surgeon can also offer most patients with obstruction or perforation of the colon the advantage of definitive resectional surgery within 24 hours, ${ }^{21}$ and this should not be difficult to organise as it becomes customary to keep an emergency theatre open throughout the day. ${ }^{22}$ These technical tasks, and cooperation with the oncologists in the study and application of the developing field of non-surgical therapy, offer wide scope to the surgeon with a special interest in the large bowel.

The 1980-2 study was carried out as part of the Grampian oncological research project and we acknowledge the support which the project received from the Endowments Research Fund of the Grampian Health Baord. All the consultant surgeons gave permission for study of their patients and we thank them for their cooperation. We are much indebted to all the general practitioners who provided information on their patients, and to Marion Campbell for statistical advice.

1 King's Fund Forum. Cancer of the colon and rectum. Br f Surg 1990;77: 1063-5. 
2 Clarke DN, Jones PF, Needham CD. Outcome in colorectal carcinoma: seven year study of a population. $B M \mathcal{F} 1980 ; 280: 431-5$.

3 Dukes CE. The classification of carcinoma of the rectum. I Path Bact 1932;35:323-32.

4 Registrar General Scotland. Annual report 1982. Edinburgh: HMSO, 1983. 5 Beart RW, Melton J, Maruta M, Dockerty MB, Frydenburg HB, O'Fallon WM. Trends in right and left colon cancer. Dis Colon Rectum 1983;26:393-8. 6 Kee F, Wilson RH, Gilliland R, Sloan JM, Rowlands BJ, Moorehead RJ. Changing site distribution of colorectal cancer. $B M \mathcal{F}$ 1992;305:158.

7 Brown SCW, Walsh S, Sykes PA. Operative mortality rate and surgery for colorectal cancer. $\mathrm{Br}$ f Surg 1988;75:645-7.

8 McArdle CS, Hole D, Hansell D, Blumgart LH, Wood CB. Prospective study of colorectal cancer in the West of Scotland: 10-year follow-up. Br f Surg 1990;77:280-2.

9 Finlay IG, Meek D, Brunton F, McArdle CS. Growth rate of hepatic metastases in colorectal carcinoma. Brf Surg 1988;75:641-4.

10 Hardcaste JD, Thomas WM. Chamberlain J Pye G, Sheffield J, James PD, 作 et al. Randomised controlled trial of faecal occult blood screening for
colorectal cancer. Lancet 1989;ii:1160-4.

11 Finlay IG, McArdle CS. Occult hepatic metastases in colorectal carcinoma. Brf Surg 1986;73:732-5.

12 Gray R, James R, Mossman J, Stenning S. AXIS-a suitable case for treatment. Brf Cancer 1991;63:841-5.

13 Taylor I, Machin D, Mullee M, Trotter G, Cooke T, West C. A randomised controlled trial of adjuvant portal vein cytotoxic perfusion in colorectal cancer. Br 7 Surg 1985;72:359-63.

14 Fieldig LP, Hitinger $R$, Grace RH, Fry JS. infusion after curative resection for colorectal adenocarcinoma. Lancet 1992;340:502-6.

15 Archer SG, Gray BN. Vascularisation of small liver metastases. $\mathrm{Br} f$ Surg 1989;76:545-8.

16 Moertel CG, Fleming TR, Macdonald HS, Haller DG, Laurie JA, Goodman PJ, et al. Levamisole and fluorouracil for adjuvant therapy of resected colon carcinoma. N Engl F Med 1990;322:352-8.

17 Fielding LP. Mesorectal excision for rectal cancer. Lancet 1993;341:471-2. 18 Collins REC. The organisation of general surgery services in a population. Ann $R$ Coll Surg Engl 1993;75:\$33-4. (College and faculty bulletin supplement.)

19 Callaghan J. Colorectal cancer in a small rural hospital. Am f Surg 1990;159: $277-81$.

20 Jackson BT. Coloproctology-a specialty in transition. Ann R Coll Surg Engl 1992;74:S63-6. (College and faculty bulletin supplement.)

1992;74:S63-6. (College and faculty bulletin supplement.) 21 Darby CR, Berry AR, Mortensen N. Managem

22 Association of Surgeons of Great Britain and Ireland. The organisation of general 22 Association of Surgeons of Great Britain and
surgical services. London: The Association, 1993.

(Accepred 13 fuly 1993)
School of Public Health

Free University of

Brussels, Brussels,

Belgium

M Dramaix, biostatistician

CUMUBAC Medical

Team, Free University of

Brussels, Brussels,

Belgium

P Hennart, director

$\mathrm{R}$ Tonglet, project manager

$\mathrm{Ph}$ Donnen, project manager

$\mathrm{R}$ Smets, paediatrician

Queen Fabiola Children's Hospital, Free University of Brussels, Brussels, Belgium

D Brasseur, paediatric

nutritionist

Natural Sciences Research

Centre, Lwiro, Zaire

P Bahewere, general

practitioner

O Mudjene, general

practitioner

Correspondence to:

Dr P Hennart, Laboratory of Epidemiology and Social Medicine, School of Public Health, (ULB), Route de Lennix, 808 B-1070

Brussels, Belgium.

\title{
Serum albumin concentration, arm circumference, and oedema and subsequent risk of dying in children in central Africa
}

\author{
MDramaix, P Hennart, D Brasseur, $\mathrm{P}$ Bahwere, $\mathrm{O}$ Mudjene, $\mathrm{R}$ Tonglet, Ph|Donnen, R Smets
}

\section{Abstract}

Objective-To measure the prognostic value of clinical, anthropometric, and biological indicators of protein energy malnutrition in hospitalised children.

Design-Hospital based follow up study from admission to discharge or death of a cohort of children.

Setting-Paediatric hospital in Zaire.

Subjects-1129 children consecutively admitted between August 1986 and October 1988.

Main outcome measures-Height, weight, arm circumference, skinfold thicknesses, serum albumin concentration, and mortality.

Results-Mortality was higher in wasted children and in those with a mid-upper arm circumference $<125 \mathrm{~mm}$, a serum albumin concentration $<16 \mathrm{~g} /$, and oedema. After multivariate analysis, serum albumin concentration was the best predictor of subsequent risk of dying. Mid-upper arm circumference and oedema, however, still contributed considerably to evaluation of mortality.

Conclusions-In this specific environment of central Africa an isolated clinical sign such as oedema is not enough to detect children with a high risk of dying among those admitted to paediatric wards with severe protein energy malnutrition. Measurement of additional indicators such as arm circumference and serum albumin concentration seems to be of crucial importance.

\section{Introduction}

In developing countries protein energy malnutrition is common among children admitted to hospital and is associated with a high morbidity and mortality. ${ }^{1-4} \mathrm{~A}$ nutritional assessment is mandatory to treat and follow these severely ill patients. Different anthropometric and biological variables have been proposed, biometry being the most commonly used tool. Major signs looked for are oedema and muscle wastage, isolated or in combination.

Most common classifications of protein energy malnutrition are usually based on weight loss compared with international reference data and the presence of oedema, which enables differentiation of kwashiorkor from marasmus. ${ }^{5}$ Different authors have found a close association between some anthropometric measurements and the risk of dying during the hospital stay. ${ }^{6-7}$ In the oedematous form of protein energy malnutrition, however, there is no simple association between mortality and the severity of weight loss, whereas the albumin concentration at admission is strongly associated with mortality. ${ }^{8}$

In central Africa all forms of protein energy malnutrition are often encountered, particularly in hospitals. Our aim was to detect from various anthropometric measurements, clinical signs, and biochemical indices very commonly performed or collected those mainly associated from the time of admission with a higher risk of dying.

Our purpose was to identify the most discriminant and predictive of these markers.

\section{Patients and methods}

The children's hospital of Lwiro is located in south Kivu in Zaire, at the eastern border of the country. In these highlands most people are living by subsistence farming, and their food supply is low in energy and protein with large seasonal variations.

Between August 1986 and October 19881129 children admitted consecutively to the paediatric hospital of Lwiro were included in the follow up study; two thirds of the children suffered from clinical protein energy malnutrition.

We analysed different variables at baseline and their association with subsequent mortality. The median age of the children was 27 months; three quarters were aged under 5 years and nearly half under 2 years. The average duration of admission to hospital was 26 days, but nearly half of the children had left the hospital within two weeks. At the time of admission 395 children suffered from gastroenteritis and 203 were dehydrated; moreover 350 had a body temperature above $37.5^{\circ} \mathrm{C}, 237$ had an infection of the lower respiratory tract, and 304 had malaria.

We studied the anthropometric indicators of height for age, weight for height, mid-upper arm circumference, and tricipital and subscapular skinfold thicknesses. Weight was measured to the nearest $10 \mathrm{~g}$. Weight scales were calibrated daily. Recumbent length 